\title{
COMUNIDADE DE PRÁTICA DE TERAPEUTAS OCUPACIONAIS INICIANTES: O INÍCIO DA PRÁTICA EM SAÚDE MENTAL
}

COMUNIDAD DE PRÁCTICA DE TERAPEUTAS OCUPACIONALES PRINCIPIANTES: INICIO DE LA PRÁCTICA EN SALUD MENTAL

COMMUNITY OF PRACTICE OF NEWLY OCCUPATIONAL THERAPISTS: THE MENTAL HEALTH PRACTICE BEGINNING

\section{Taís Quevedo Marcolino', Regina Helena Vitale Torkomian Joaquim², Angélica da Silva Araújo ${ }^{3}$, Ana Carolina Carreira de Mello ${ }^{4}$, Aline Maria de Medeiros Rodrigues Reali $^{5}$}

\begin{abstract}
RESUMO
O início da prática é um período de intensa socialização profissional e de vivências dilemáticas e estressantes. Este artigo apresenta parte dos resultados de uma pesquisa-ação que objetivou compreender aspectos do desenvolvimento profissional em terapia ocupacional, e contou com participação de seis terapeutas ocupacionais iniciantes, da pesquisadora e de dois terapeutas ocupacionais experientes em uma comunidade de prática, com encontros presenciais gravados e transcritos, e atividades virtuais - dados analisados tematicamente. A temática dos dilemas vividos na prática iniciante e a construção de sentidos sobre eles organizaram-se em quatro subtemas: O não-saber como alimento para o desenvolvimento profissional; Serterapeuta na saúde mental; O uso de atividades em saúde mental e o que é específico em terapia ocupacional; Aprender a encontrar o foco em atendimentos de curto tempo. Esperamos que este artigo possa ampliar reflexões sobre a formação inicial e continuada em terapia ocupacional, além de indicar novas possibilidades de pesquisa na temática.
\end{abstract}

\section{PALAVRAS-CHAVE}

Terapia ocupacional; Educação continuada; Saúde mental.

1 Terapeuta ocupacional pela Universidade Federal de São Carlos, Mestre e Doutora em Educação pela Universidade Federal de São Carlos. Professora Adjunta. Departamento de Terapia Ocupacional da Universidade Federal de São Carlos, São Carlos, SP, Brasil. taisquevedo@ gmail.com Researcher ID C-8110-2014.ORCID 0000-0002-9694-5118

2 Terapeuta ocupacional pela Universidade Federal de São Carlos, Mestre e Doutora em Educação Especial pela Universidade Federal de São Carlos. Professora Adjunta. Rodovia Washington Luiz, km 235, São Carlos, SP, Brazil, CEP 13565-905, joaquimrhvt@gmail.com, +55 16 33518111. ORCID 0000-0003-3700-397X

3 Terapeuta ocupacional pela Universidade de São Paulo, Mestre em Ciências pela Universidade de São Paulo e Doutoranda em Terapia Ocupacional pela Universidade Federal de São Carlos. Diretora no Hospital Estadual de Américo Brasiliense. Programa de Pós-Graduação em Terapia Ocupacional da Universidade Federal de São Carlos, São Carlos, SP, Brasil. angelicadsaraujo@gmail.com. Researcher ID Q-28842018. ORCID https://orcid.org/0000-0001-8625-3620

4 Terapeuta ocupacional pela Universidade de São Paulo, Mestranda em Terapia Ocupacional pela Universidade Federal de São Carlos. Estudante de Pós-Graduação. Programa de Pós-Graduação em Terapia Ocupacional da Universidade Federal de São Carlos, São Carlos, SP, Brasil. anacarolinacmello@gmail.com. Researcher ID C-9432-2017. ORCID https://orcid.org/0000-0002-7021-3410

5 Psicóloga pela Universidade de São Paulo, Mestre em Educação Especial pela Universidade Federal de São Carlos, Doutora em Psicologia pela Universidade de São Paulo. Professora Titular. Departamento de Teorias e Práticas Pedagógicas da Universidade Federal de São Carlos, São Carlos, SP, Brasil. alinereali@gmail.com. ORCID 0000-0003-4915-8127 


\section{RESUMEN:}

El inicio de la práctica profesional es un período de intensa socialización y vivencias de dilemas yestrés. Este artículo presenta parte de los resultados de una investigación-acción con el objetivo de comprender algunos aspectos del desarrollo profesional en terapia ocupacional; participan seis terapeutas ocupacionales que inician su trabajo, la investigadora y dos terapeutas ocupacionales con experiencia, en una comunidad de práctica. Los encuentros presenciales fueron grabados y transcritos, además de actividades virtuales y los datos fueron analizados por tema. La temática de los dilemas vividos en la práctica inicialy la construcción de significados de éstos se organizaron en cuatro subtemas: La falta de conocimiento para el desarrollo profesional; ser terapeuta en la salud mental; el uso de actividades especificas de TO en salud mental y qué es para terapia ocupacional; aprender a encontrar el foco de la intervención de corto tiempo. Esperamos que este artículo pueda ampliar reflexiones sobre la formación inicial y continuada en terapia ocupacional, e indicar nuevas posibilidades de investigación en la temática.

\section{PALABRAS CLAVE}

Terapia ocupacional; Educación contínua; Salud mental.

\section{ABSTRACT}

The beginning of practice has been considered an intense professional period of socialization and high level of stress. This article presents some results from an Action Research which included the participation of six beginners occupational therapists, the researcher and two experienced occupational therapists in a community of practice. The meetings were recording and transcribing beside virtual activities. All data were thematically analyzed. The theme of dilemmas in the beginning of practice and the construction of meaning were organized in four themes: Non-knowing nurturing professional development; being a therapist in mental health; use of activities and occupational therapy specificity; learning to find the focus of the intervention on short-term care. We hope this study could expand reflections on initial and continuing training in occupational therapy, and to indicate new possibilities for research in the subject.

\section{KEYWORDS}

Occupational therapy. Continuing education; Mental health.

Recibido: 05 Septiembre 2018

Aceptado: 11 Septiembre 2019 


\section{INTRODUÇÃO}

O início da carreira é um período de intensa socialização e aprendizagem profissional, no qual os recém-graduados precisam lidar com a realidade do trabalho de modo diferente do que o que foi vivenciado na formação inicial (Fitzgerald, Moores, Coleman, Fleming, 2015).

Tryssenaar e Perkins (2001) identificaram quatro estágios desse processo de transição: a ansiedade pela prática livre de supervisores e status profissional (Transição); a experimentação da prática com momentos de prazer e angústia (Euforia e Angústia); o encontro com a realidade nem sempre prazerosa do trabalho (Realidade da Prática); e o início de um novo relacionamento com o mundo profissional (Adaptação).

Nesses estágios, há temas recorrentes como a competência profissional centrada nas habilidades técnicas e no bem-estar dos clientes; a política das instituições empregadoras; momentos de tensões ligadas a conhecimento, habilidades e atitudes que afetam a vida profissional e pessoal (medo do desânimo/desencanto com a profissão, controle do ritmo e do estresse) (Tryssenaar, Perkins, 2001).

Os principais fatores estressores nesse período relacionam-se à identidade profissional (falta de reconhecimento, incerteza do papel profissional, desvalorização profissional); às características pessoais (insegurança); ao relacionamento com a equipe (dificuldades de comunicação e gerenciamento de conflitos). Além disso, falta de suporte, supervisão, feedback e de trabalho articulado com profissionais experientes; pouco tempo para reflexão; falta de conhecimentos, habilidades e de contextualização; ambiente físico (limitação de recursos e espaços); e ajustamento às regras do trabaIho são outros fatores estressores desse período (Hunt, Kennedy-Jones, 2010; Morley, 2006; 2007; Morley, Rugg, Drew al., 2007; Nayar, Gray, Blijlevens, 2013; Rugg, 2003; Toal-Sullivan, 2006).

Estratégias para enfrentamento das dificuldades e melhoria da aprendizagem abarcam o acesso regular à supervisão com feedback sobre seu desempenho; estratégias de manejo do tempo; suporte profissional e social (colegas, família, amigos, grupos de suporte); educação continuada e oportunidades de reflexão sobre a prática (Hunt, Kennedy-Jones, 2010; Morley, 2006; 2007; Morley, 2006; 2007; Lloyd, King, Ryan, 2007).
No Brasil, o campo da saúde mental é um importante cenário de prática profissional e vem recebendo cada vez mais investimento das pesquisas brasileiras (Lins, Matsukura, 2015; Ricci, Marques, Marcolino, 2018). Lins e Matsukura (2015) indicam que terapeutas ocupacionais iniciantes apresentam segurança para atuar em saúde mental.

Entretanto, estudos brasileiros (Mângia, Muramoto, Marques, 2010; Juns, Lancman, 2011, Lins, Matsukura, 2015) destacam dificuldades dos profissionais iniciantes em relação à construção de novas formas de atuação para as políticas de saúde mental e às funções de gestão (Mângia et al., 2010) bem como a questões de identidade profissional na saúde mental (Juns, Lancman, 2011). A formação continuada e o acesso à supervisão também são apontadas como estratégias para enfrentamento das dificuldades iniciais no Brasil (Lins, Matsukura,2015; Mângia et al., 2010).

Outro aspecto próprio do início de carreira é a característica do raciocínio clínico. Algumas pesquisas (Spalding, 2000; Mitchell, Unsworth, 2005; Unsworth, Baker, 2016; Adam, Peters, Chipchase, 2013) evidenciam que terapeutas ocupacionais iniciantes possuem mais aderência a regras gerais em detrimento das singularidades da prática, principalmente quando vivenciam situações novas e precisam estabelecer prioridades. Além disso, iniciantes utilizam mais o raciocínio voltado para procedimentos, centrado no conhecimento e na compreensão do problema do sujeito alvo. Por outro lado, terapeutas mais experientes usam combinação de raciocínios em um fluxo contínuo de ideias, e possuem maior compreensão do ponto de vista do sujeito, além de compreender os fatores que podem limitar a terapia (Unsworth, Baker, 2016). Adams et al. (2013) destacam que esses atributos podem ser identificados nos profissionais iniciantes, entretanto, a literatura não define os atributos específicos requeridos para início na prática profissional.

Nessa direção, como parte dos resultados de uma pesquisa-ação interessada em compreender aspectos do desenvolvimento profissional e do raciocínio clínico de terapeutas ocupacionais em início de carreira, o presente artigo discute os dilemas, as dificuldades e os sentidos construídos por esses profissionais em uma comunidade de prática. 


\section{Metodo}

\section{Tipo de estudo}

Trata-se de uma pesquisa-ação participativa (Toledo, Giatti, Jacobi, 2014), modalidade qualitativa de pesquisa interessada tanto na produção de conhecimentos sobre a prática como em seu aprimoramento, construída em modos colaborativos de trabalho. A intervenção da pesquisa-ação participativa organizou-se em uma Comunidade de Prática (CoP) (Wenger, 1998), estratégia constituída pelo engajamento mútuo de pessoas em um empreendimento comum, demandando negociação de significados ao compartilhar e produzir repertórios, conhecimentos e modos de fazer. A CoP demanda a interação entre a participação dos sujeitos e o que é produzido por essa participação, organizando ações e interações, favorecendo a produção de novos sentidos e novas formas de participação.

Assim, buscou-se compreender os principais aspectos circundantes a esse momento da carreira profissional por meio da participação ativa de terapeutas ocupacionais em início de carreira discutindo questões oriundas de suas práticas.

\section{Participantes}

Participaram da CoP, seis terapeutas ocupacionais graduados, em início de carreira, matriculados no segundo ano de um curso de pós-graduação, de tipo especialização, em Terapia Ocupacional em Saúde Mental, oferecido por uma universidade pública do Estado de São Paulo. A CoP também teve a participação da pesquisadora e de outras duas terapeutas ocupacionais experientes - professoras e supervisoras do referido curso, com mais de dez anos de prática clínica na área.

O curso de especialização tinha duração de dois anos, e contava com atividades assistenciais em equipes multiprofissionais em diferentes serviços de saúde mental (centro de atenção psicossocial, enfermaria e serviço de interconsulta em saúde mental em hospital geral e ambulatórios especializados para crise e esquizofrenia) em revezamento de três meses, com supervisão de diferentes terapeutas ocupacionais. Cabe ressaltar que os contextos institucionais não foram alvo de investigação direta.

\section{Coleta de dados}

A coleta de dados ocorreu em 18 encontros quinzenais e presenciais ao longo de dez meses (março a dezembro de 2007), com duração aproximada de uma hora, gravados em áudio e transcritos. A partir da leitura das transcrições, a pesquisadora identificava os temas discutidos e elaborava uma crônica do grupo (Marcolino, Reali, 2016), que se constituía em uma narrativa cronológica do encontro, contendo as interpretações da pesquisadora e excertos das falas como justificativas. A crônica era disponibilizada às participantes antes de cada próximo encontro para que analisassem as interpretações, funcionando assim como uma ferramenta não-dialética que propiciava uma análise de dados colaborativa (Marcolino, Reali, 2016).

Além disso, as profissionais iniciantes mantinham um diário reflexivo, enviado à pesquisadora antes de cada encontro, para o qual havia devolutiva, com questões reflexivas, fomentando maior aprofundamento na reflexão sobre a prática. O constante feedback e fluxo entre diários e encontros presenciais favoreceu um movimento de retroalimentação, no qual cada elemento era influenciado pelos demais (Marcolino, Lourenço, Reali, 2017).

No início da CoP, a pesquisadora assumiu a responsabilidade de introduzir a discussão nos encontros grupais, explicitando os temas refletidos nos diários reflexivos. Na medida em que a CoP foi se consolidando, os temas discutidos e as estratégias utilizadas (compartilhar narrativas sobre a prática, leitura de textos disparadores) foram sendo decididos pelas participantes.

\section{Análise dos dados}

As transcrições dos encontros e os diários reflexivos foram analisados tematicamente (Minayo, 2010) pela pesquisadora, após a finalização da CoP. Tal análise se deu por meio da identificação de núcleos de sentido que compunham um mesmo tema. 
A análise dos dados aconteceu em quatro etapas: 1) análise temática de todas as transcrições, resultando em três temas que explicitam os conteúdos trabalhados nos encontros (a construção na pesquisa-ação; ser terapeuta ocupacional iniciante; a assistência em terapia ocupacional); 2) nova análise temática de cada tema de modo a identificar subtemas; 3 ) análise da linha do tempo de modo a explicitar como esses temas foram se constituindo ao longo da pesquisa; 4) validação do processo de análise junto às demais participantes da $\mathrm{CoP}$, em encontro presencial.

Neste artigo, serão discutidos um dos principais aspectos identificados na pesquisa-ação: os dilemas, as dificuldades e os sentidos construídos por esses terapeutas ocupacionais iniciantes integrantes do tema "ser terapeuta ocupacional iniciante".

\section{Aspectos éticos}

A pesquisa foi aprovada pelo Comitê de Ética do Centro Universitário de Araraquara sob parecer número 476. O nome das participantes é fictício e foi escolhido por elas, sendo: Clarice, Marisa, Fernanda, Mariana, Luiza e Isadora, e as profissionais experientes: Lúcia e Tássia.

Ressalta-se que os dados brutos e as análises encontram-se em posse da pesquisadora e seguem as normas de sigilo definidas pela ética em pesquisa com seres humanos no Brasil, pela Resolução 466/2012.

\section{ReSUltADOS}

foram identificados quatro subtemas para o tema "ser terapeuta ocupacional iniciante": a) O não-saber como alimento para o desenvolvimento profissional; b) Ser terapeuta na saúde mental; c) Sobre o uso de atividades em saúde mental e o que é específico em terapia ocupacional; d) Aprender a encontrar o foco em atendimentos de tempo curto.

A produção de sentido sobre essas questões foi construída na CoP, ora em apenas um encontro presencial, ora em muitos encontros (nem sempre sequenciais). Assim, a apresentação desses resultados buscará evidenciar como esses temas foram postos para discussão e como, ao longo do tempo, novas construções de sentido sobre eles foram sendo elaboradas.

\section{O não-saber como alimento para o desenvolvimento profissional}

Esse dilema abarcou aspectos relacionados às crenças sobre o que é um terapeuta competente. Esse tema foi discutido em quatro encontros $(20,60,140,170)$, tendo iniciado com as colocações de Luiza sobre suas expectativas em ser uma "terapeuta melhor" após o primeiro ano de prática; e de Mariana, e sua sensação de que já "deveria saber".

"[...] o raciocínio [...] com o paciente, parece que a cada dia está piorando, [...] eu estava com uma ilusão que [...] agora no segundo ano eu ia estar melhor [...]" (Luiza, 20 encontro)

"[...] por eu ser uma terapeuta nova [...] eu fico com a ideia de que eu deveria saber [...]. E [...] é muito bom [...] poder ver [...] que a gente não vai saber muitas coisas, porque isso também vem da possibilidade de construção [...]" (Mariana, 6o encontro)

Essa questão retornou nos encontros finais da $\mathrm{CoP}(140$ e 170) quando as participantes destacaram que compartilhar reflexões sobre a prática na CoP possibilitou compreender o não-saber. Inicialmente identificado como imaturidade profissional, mesmo quando as profissionais iniciantes tinham um sentimento de maestria (sentimento característico do saber fazer na prática: "sei ser terapeuta ocupacional") (Schell, Schell, 2018), e que pode se transformar em uma perspectiva de desenvolvimento profissional, o não-saber que pode levar à aprendizagem.

"Eu fico em crise por ainda ter essas dúvidas '[...] mas eu já sou formada há dois anos' [...] porque quando eu em ação, [...] sei ser terapeuta ocupacional [...] mas quando eu vou falar ou pensar sobre isso [...] eu fico totalmente atrapalhada [...]" (Marisa, 140 encontro)

"[...] desde que elas [as dúvidas] não sejam sentidas como alguma coisa que não devia acontecer, porque aí você se sente errado, [...] incompetente." (Lúcia, 140 encontro) 
"[...] a gente vem com certos mitos [...] de que vai para a prática [...] então não vai mais ter dúvidas, e [...] é um tempo que a gente vai vendo que é natural, e acho que também esse grupo [...] ajuda a gente a perceber que pode compartilhar, [...] pensar sobre as coisas, [...] estudar, pode buscar pessoas, [...] agora eu me sinto mais tranquila [...]" (Mariana, 170 encontro)

\section{Ser terapeuta na saúde mental}

O tema "ser terapeuta na saúde mental" foi trabalhado em três encontros na $\mathrm{CoP}(40,120,170)$, tendo sido inaugurado com as colocações de Clarice de que o trabalho de cuidado em saúde mental estava se mostrando diferente da realidade que imaginava, pois via colegas desgastados com o trabalho. Alguns dos motivos discutidos no processo reflexivo foram (a) o intenso envolvimento subjetivo necessário para a construção da relação de cuidado que, por vezes, pode favorecer identificações com o sofrimento dos pacientes, e (b) a fragilidade dos recursos institucionais para cuidar de casos muito graves, e de recursos subjetivos/emocionais por parte dos profissionais.

“[...] no início a gente vem com uma garra tão grande, [...] vai sendo muito mobilizada por essa garra, [...] com o tempo, [...] a gente vai se deparando com uma realidade que me parece ser muito diferente daquela do começo e [...] me preocupa muito pensar da onde eu vou tirar força para continuar [...] eu vejo [...] muitas pessoas desgastadas [...] com a clínica [...], porque a gente tem que investir demais no nosso ser [...]" (Clarice, 40 encontro)

"[...] dá medo, porque são situações tão limites [...] parece que você vai sucumbir junto, [...] porque você vai vivendo muito perto [...] vai ficando muito identificada [com o sofrimento dos pacientes]" (Mariana, 120 encontro)

"Até aonde a gente vai? Qual é o nosso limite? [...] é uma clientela [casos graves, como pacientes borderline] que parece que vai ficando sem lugar [...]. Às vezes, até ferramenta emocional [...] falta [...]." (Mariana, 170 encontro)

As construções na CoP, para discutir tais processos complexos no cuidado em saúde mental, abarcaram a necessidade de investir em si mesma, subjetivamente, por meio de processos de autoconhecimento; e de dividir o sofrimento com as colegas de trabalho, além de pedir ajuda para compreender melhor situações. Cuidar de sua saúde mental e de ter uma vida que não seja preenchida somente pelo trabalho também foi uma estratégia reconhecida, comparando-a, inclusive, ao cuidado em terapia ocupacional oferecido aos pacientes, quando os mesmos são estimulados a ampliarem suas atividades e a se divertirem.

"Acho que um espaço é a terapia, e outro fundamental é a gente estar juntas, poder dividir um pouco do sofrimento que vai passando, um pouco da alegria [...]" (Clarice, 40 encontro)

“... a gente fala para os nossos pacientes 'vocês precisam ampliar o seu repertório, [...], vamos fazer mais coisas, [...]' [...] 'que é que eu tenho ampliado?' [...] até [...] de pedir ajuda mesmo, [...] a gente fala para os nossos pacientes 'olha, pede ajuda, [...], não há problema nenhum nisso' e a gente não consegue [...]" (Luiza, 40 encontro)

Outra estratégia discutida foi a valorização dos recursos técnicos do terapeuta, para ajudá-lo a se perceber na relação e a fazer escolhas que viabilizem o cuidado. Para isso, refletiu-se sobre a importância de dimensionar que a pessoa, que está sendo cuidada, tem uma vida que vai além da terapia.

"[...] a gente participa de um pedaço da vida dos nossos pacientes [...] ele tem uma vida antes e, espero, vai ter depois, e eu sei que em situações muito graves [...] parece que isso não se aplica, porque [...] parece que esse tratamento é a última salvação. [...] Mas por outro 
lado, tem uma certa organização que existe [...] e que as pessoas vão buscar para resolver as situações e continuar vivendo. Isso me ajuda a pensar um pouco, a não ficar com toda a carga, [...] diante da experiência de impossibilidade que a gente tem [...] nessas situações." (Lúcia, 150 encontro)

"[...] eu fui pensando na contratransferência individual [...] de cada uma de nós, [...] de como é insuportável para a gente lidar com isso, e [...] para onde a gente leva isso? [...] eu acho que a importância da gente se dar conta disso [de como o profissional se coloca na relação de cuidado] [...] é de pensar [...] como eu vou responder a isso." (Lúcia, 170 encontro)

\section{Sobre o uso de atividades em saúde mental e o que é específico em terapia ocupacional}

O uso de atividades como instrumento específico da terapia ocupacional foi a questão que deflagrou o dilema de identidade profissional na CoP, nos encontros (6o, 8o e 140). Inicialmente, esse tema foi motivado pela discussão dos procedimentos em terapia ocupacional em saúde mental pelo uso de atividades, ora questionando se há diferenças com práticas psicoterápicas, ora de uma forma mais integrada, atrelada aos objetivos da terapia ocupacional para o sujeito-alvo das intervenções.

"[...] será que é a mesma coisa que um grupo [que utiliza atividade como recurso] em que um [...] um psicólogo esteja coordenando do que um grupo de terapia ocupacional? [...] " (Mariana, 6o encontro)

"[...] porque eu acho que se fala muito [...] que o diferencial é a atividade, [...] é trabalhar com o material, [...] para mim não faz [...] sentido. [...] o psicólogo também está fazendo atividade, [...] eu acho mesmo que o diferencial [...] é o objetivo [...] daí a gente pode usar os recursos que [...] quiser, [...] pode usar material, a gente faz atividade, faz na sala, vai na comunidade, [...]" (Marisa, 8o encontro)
"[...] auxiliar essa pessoa a se ver [...] e se mover nas suas ações, nos seus projetos, nas suas atividades, [...] é uma questão de qualificação, da mesma forma como o teu paciente se apropria daquilo, dizendo que faz terapia ocupacional, [...] e isso faz bem para ele, [...] ele está levando essa experiência. [...] e a gente sente isso como profundamente desqualificador? [...]" (Lúcia, 140 encontro)

Entretanto, mesmo diante de ideias que fazem sentido, Fernanda se questiona porque, na prática, esse dilema ainda persiste.

"[...] isso que a gente está conversando hoje, faz total sentido [...] mas por que é que quando eu estou na prática, me pega de um jeito que parece que é um vírus [...] 'mas, não é terapia ocupacional, porque que ela quer dar argila para ela? Ela é psicóloga, vai dar argila' [...] acho que é uma imaturidade profissional [...], porque faz total sentido, [...]" (Fernanda, 140 encontro)

\section{Aprender a encontrar o foco em atendimentos de curto tempo}

Outro dilema presente nas discussões da CoP, nos encontros 120 e 150, abarcou a negociação com procedimentos institucionais, principalmente pela necessidade de encontrar rapidamente o foco (prioridades do tratamento) em um curto espaço de tempo, pela alta hospitalar ou pela morte.

Nesses dois momentos, as profissionais iniciantes procuraram nomear a questão temporal como uma tensão presente em seu raciocínio, vivida no primeiro ano de prática com muito sofrimento, mas que ainda não era uma tarefa fácil. Nesse contexto, fazia-se constante a negociação com a realidade institucional para encontrar o foco em tão curto tempo e construir histórias significativas com os pacientes.

"[...] eu lembro que a gente ficava muito angustiada com essa questão do tempo, então a 
gente [...] não ia embora às seis horas, [...], eram oito horas da noite [e a gente] estava atendendo paciente [...] [quando não está] claro o foco, [...] vejo que não adianta eu ficar aqui o dia inteiro com o paciente." (Mariana, 120 encontro)

"Porque é uma experiência de um tempo diferente, de um ritmo diferente, [...] você tem que encontrar o foco, [...] na supervisão, '[...] qual é o foco? Qual é o foco?' [...] surgem milhares de coisas na terapia ocupacional [...] É um tempo muito restrito, parece que você não pode pensar, você tem que agir, pensar, agir, pensar, agir, pensar, agir, e assusta [...]" (Mariana, 150 encontro)

\section{Discussão}

Os resultados aqui discutidos abarcam construções que se sustentam em um processo de aprendizagem colaborativa, cujo elemento central foi a reflexão sobre a prática (Marcolino et al., 2017; Schön, 2000), aspecto potente para a transição e o desenvolvimento profissional (Hunt, Kennedy-Jones, 2010; Morley, 2006).

Este estudo situa-se em um contexto específico de pesquisa sobre o exercício profissional e aprendizagem da prática para terapeutas ocupacionais (especialização em terapia ocupacional em saúde mental) e os dilemas e as construções encontradas indicam ressonância com resultados de outros estudos (Hunt, Kennedy-Jones, 2010; Morley, 2006; 2007; Morley et al., 2007; Nayar et al., 2013; Rugg, 2003; Toal-Sullivan, 2006; Spalding, 2000; Mitchell, Unsworth, 2005; Lins, Matsukura, 2015; Mângia et al., 2O10; Juns, Lancman, 2011).

Considerando a prática profissional no segundo ano do curso de especialização como uma prática de transição, foi possível relacionar as experiências vividas pelas terapeutas ocupacionais iniciantes aos estágios do período de transição estudante-terapeuta (Tryssenaar, Perkins, 2001).

No Estágio de Euforia e Angústia (Tryssenaar, Perkins, 2001), a competência profissional é um dos alvos principais das reflexões dos iniciantes, e foi tema de maior produção na CoP. Em relação à competência auto centrada, a crença de que as profissionais já deveriam saber e a fantasia da terapeuta ocupacional ideal foram sendo substituídas por uma compreensão de que ter dúvidas faz parte da prática e pode impulsionar o desenvolvimento, levando o profissional a refletir, estudar e buscar ajuda.

Coffelt e Gabriel (2017) destacam que profissionais iniciantes valorizam processos de desenvolvimento profissional bem como a colaboração dos colegas nesse percurso, e que buscam atividades formais e informais de modo a construir ativamente aprendizagem significativas para a continuidade do aprendizado competente da prática. Adams et al. (2013) explicitam que, além do conhecimento sobre a doença, tratamento, reabilitação e competência de comunicação, comportamentos de auto reflexão e avaliação são atributos fundamentais para o desenvolvimento profissional.

As preocupações de competência centradas no cliente estiveram presentes o tempo todo, quando se discutia qual a melhor forma de agir e de compreender a situação, para que o melhor para o sujeito pudesse ser feito, como nas discussões sobre a fragilidade institucional para casos mais complexos e do desafio de, em pouco tempo, construir histórias significativas com os pacientes.

Essas discussões também podem ser compreendidas como evidências da negociação com a realidade da prática, buscando-se pela compreensão do ponto de vista do sujeito e de seu contexto (Spalding, 2000; Mitchell, Unsworth, 2005), investindo e se responsabilizando pelos pacientes. Esses resultados são similares aos de Lloyd, King e Ryan (2007) quando evidenciam que terapeutas ocupacionais iniciantes possuem maior responsabilidade sobre os pacientes quando em serviços comunitários de saúde mental.

Tryssenaar e Perkins (2001) também relatam que os profissionais iniciantes vivem momentos de choque, em que situações profissionais estressantes afetam a vida pessoal, com sentimentos de desânimo, medo, desesperança. Esses sentimentos foram vividos pelas profissionais, porém, pareceram estar relacionados mais ao cuidado em saúde mental, do que a outras questões próprias do início da carreira.

Basset e Lloyd (2001) e Scanlan e Still (2013), em estudos com mais de dez anos de diferença, ainda ressaltam a grande probabilidade da vivência de burnout na 
saúde mental, tendo como principais fatores a natureza dos clientes (cronicidade, dificuldades e demora de mudanças no estilo de vida) e as implicações do tratamento (longo período de tratamento, intensidade do investimento na aliança terapêutica, expectativas mal ajustadas em relação aos clientes). Esses sentimentos também foram reconhecidos pelas profissionais experientes e a CoP conseguiu produzir entendimentos sobre a importância de aprender a analisar como cada profissional se envolve nas situações mais complexas e como pode responder às demandas sem carregar o peso todo em si, como estratégia de ampliação da resiliência pessoal (Scanlan, Still, 2013).

Dificuldades com a identidade profissional são presentes no início da carreira (Hunt, Kennedy-Jones, 2010; Morley, 2006; 2007; Morley et al., 2007; Nayar et al., 2013; Rugg, 2003; Toal-Sullivan, 2006), em profissionais mais experientes (Edwards, Dirette, 2010) e também no campo da saúde mental, caracterizando-se um importante fator estressor (Lloyd et al., 2007; Basset, Lloyd, 2001). Em nosso trabalho, esse dilema esteve ligado à tentativa de reconhecimento do que é específico da profissão no campo da saúde mental, inicialmente atrelado ao uso de atividades.

Embora os contextos de atuação profissional não tenham sido explorados de modo mais aprofundado nesta pesquisa, cabe ressaltar que o cuidado em saúde mental no Brasil pauta-se nos princípios da reabilitação psicossocial (Morato, Lussi, 2018). Para esta abordagem, há menor delimitação dos núcleos profissionais específicos; o foco é o campo da saúde mental e os procedimentos relacionais são fortemente valorizados, sendo comum que diferentes categorias profissionais utilizem as atividades como um recurso para mediar as relações. Essa questão usualmente produz tensionamentos em torno da identidade profissional para terapeutas ocupacionais no campo da saúde mental (Juns, Lancman, 2011).

Entretanto, no processo de reflexão coletiva e colaborativa sobre a prática, esse dilema encontrou novo sentido na compreensão de que o que é específico está mais próximo dos objetivos de nossas intervenções: da pessoa ser mais ativa em sua vida.

Essa questão é interessante tendo em vista que há mais de duas décadas é consenso para a profissão que o uso de atividades terapêuticas não nos identifica, e que o cuidado em saúde mental demanda intervenções contextuais, comunitárias e que favoreçam a construção de sentidos no cotidiano (Lins, Matsukura, 2015; Mângia et al., 2010; Juns, Lancman, 2011). Entretanto, o questionamento feito por Fernanda, "mas por que é que quando eu estou na prática isso me pega de um jeito que parece que é um vírus [...]?", ainda nos leva a questionar como, na formação inicial, essas questões vêm sendo trabalhadas ou mesmo se há problemas da ordem da identidade profissional que ainda precisem de maiores investigações.

Outro resultado deste estudo abarca a explicitação de tensões ligadas à necessidade de considerar aspectos contextuais da realidade institucional (como o curto período de tempo disponível para desenvolverem o processo terapêutico) para encontrar o foco do trabaIho e conseguirem construir histórias significativas com os pacientes. Essas considerações das profissionais se aproximam dos estudos sobre raciocínio clínico em terapia ocupacional, uma vez que abrangem aspectos ligados ao raciocínio pragmático - direcionado à influência dos contextos de prática na terapia, ao raciocínio diagnóstico - direcionado à avaliação por meio da criação de uma imagem clínica do paciente, e ao raciocínio narrativo - direcionado à criação de histórias significativas ao longo do processo terapêutico (Schell, Schell, 2018).

Além disso, ao tecer considerações sobre a importância de ter em mente que a pessoa que está sendo cuidada tem uma vida antes e depois do momento presente, as profissionais participantes se aproximam, ainda que apenas introdutoriamente, do que na literatura tem sido denominado de raciocínio condicional, caracterizado por Mattingly e Fleming (1994) como um pensamento que considera contextos temporais mais amplos da vida dos pacientes. Embora as profissionais tenham abarcado esses diferentes modos de raciocínio, estudos mostram que é comum que terapeutas ocupacionais iniciantes tenham mais dificuldades para avaliar o contexto como um todo e estabelecer prioridades, principalmente em situações novas, o que vai ao encontro do fato de as participantes terem vivenciado essas situações como tensões (Spalding, 2000; Mitchell, Unsworth, 2005; Schell, Schell, 2018; Unsworth, Baker, 2016; Shafaroodi, Kamali, Parvizy, Hassani Mehraban, O’Toole 2014).

As profissionais iniciantes, deste estudo, referem melhora nessa habilidade, mas ainda sentem dificuldades para 
realizar esse trabalho. Dada a complexidade desse tipo de intervenção, podemos levantar outras questões que se colocam para investigação: como se dá a aprendizagem dessas habilidades? Quais os principais contextos nos quais tais habilidades são demandadas? Quais estratégias apresentam melhores evidências para esse tipo de intervenção?

De modo geral, os resultados deste estudo corroboram com estudos anglo-saxões (Hunt, Kennedy-Jones, 2010; Morley, 2006; 2007; Morley et al., 2007; Nayar et al., 2013; Rugg, 2003; Toal-Sullivan, 2006) e brasileiros (Lins, Matsukura, 2015; Mângia et al., 2010; Juns, Lancman, 2011) ligados à formação e prática profissional iniciante em terapia ocupacional. Cabe ressaltar que os principais dilemas brasileiros abarcam a formação para as políticas públicas e a gestão de serviços (Lins, Matsukura, 2015; Mângia et al., 2010). Como o presente estudo focalizou o desenvolvimento profissional da perspectiva do raciocínio clínico, aspectos mais específicos em terapia ocupacional foram evidenciados.

Dado que se almeja práticas baseadas em evidências para garantir credibilidade profissional e aumentar a qualidade dos resultados com os clientes (Coffelt, Gabriel, 2017), compreender os aspectos dilemáticos da prática iniciante poderá fomentar práticas formativas-reflexivas em torno dos dilemas evidenciados, estimulando o debate e a avaliação de estratégias educacionais na formação inicial e continuada.

\section{Considerações Finais}

Este artigo discute construções de sentido realizadas no encontro entre profissionais iniciantes e experientes em torno de dilemas comuns a profissionais iniciantes. Tais dilemas abarcam o não-saber como alimento para o desenvolvimento profissional; ser terapeuta na saúde mental; o uso de atividades em saúde mental e o que é específico em terapia ocupacional; e aprender a encontrar o foco em atendimentos de curto tempo.

Além de explorar aspectos conflituosos e dilemáticos do início da prática em terapia ocupacional na saúde mental, o estudo indica caminhos para a ampliação da reflexão sobre a formação profissional e também apresenta questões de pesquisa que podem ser exploradas em outros estudos.
Desse modo, esperamos que este artigo possa colaborar ampliando as reflexões em projetos de ensino da prática em terapia ocupacional tanto na formação inicial como continuada e indicar novas possibilidades de pesquisa na temática.

Financiamento: Fundação de Amparo à Pesquisa do Estado de São Paulo/ FAPESP 2006/07152-7

\section{RefERÊNCIAS BibLIOGRÁFICAS}

Adam, K., Peters, S., Chipchase, L. (2013) Knowledge, skills and professional behaviours required by occupational therapist and physiotherapist beginning practitioners in work-related practice: A systematic review. Austr Occup Ther J, 60, 76-84. DOI: http:// dx.doi.org/10.1111/1440-1630.12006

Basset, H., Lloyd, C. (2001) Occupational therapy in mental health: managing stress and burnout. Brit J Occup Therapy, 64 (8), 406-11.

Coffelt, K. J., Gabriel, L.S. (2017) Continuing Competence Trends of Occupational Therapy Practitioners. Open JOccup Ther, 5(1), art. 4. DOI: http://dx.doi.org/10.15453/2168-6408.1268

Edwards, H., Dirette, D. (2010) The relationship between professional identity and burnout among occupational therapists. Occup Ther Health Care, 24(2), 109-129. DOI: http://dx.doi. org/10.3109/07380570903329610

Fitzgerald, C., Moores, A., Coleman, A., Fleming, J. (2015) Supporting new graduate professional development: A clinical learning framework. Austr Occup Ther J, 62, 13-20. DOI: http://dx.doi. org/10.1111/1440-1630.12165

Hunt, K. \& Kennedy-Jones, M. (2010) Novice occupational therapists' perceptions of readiness to undertake fieldwork supervision. Austr Occup Ther Journal, 57(6), 394-400. DOI: http://dx.doi. org/10.1111/j.1440-1630.2010.00859.x

Juns, A. C., Lancman, S. (2011) O trabalho interdisciplinar no CAPS e a especificidade do trabalho do terapeuta ocupacional. Rev Ter Ocup Univ São Paulo, 22(1), 27-35. DOI: http://dx.doi.org/10.11606/ issn.2238-6149.v22i1p27-35

Lins, S., Matsukura, T.S. (2015) A formação graduada do terapeuta ocupacional no campo da saúde mental: a perspectiva de discentes e egressos. Cad Bras Ter Ocup, 23 (4), 689-99. DOI: http://dx.doi. org/10.4322/0104-4931.ctoAO0613

Lloyd, C., King, R., Ryan, L. (2007) The Challenge of Working in Mental Health Settings: Perceptions of Newly Graduated Occupational Therapists. Brit J Occup Therapy, 70(11), 460-70. DOI: http:// dx.doi.org/10.1177/030802260707001102

Mângia, E. F., Muramoto, M. T., Marques, A. L. M. (2010) Formação profissional e serviços de saúde mental no SUS: estudo sobre a inserção de egressos do Curso de Terapia Ocupacional da 
FMUSP. Rev Ter Ocup Univ São Paulo, 21(2), 148-157. DOI: http:// dx.doi.org/10.11606/issn.2238-6149.v21i2p148-157

Marcolino, T. Q., Reali, A. M. M. R. (2016) Crônicas do grupo: ferramenta para análise colaborativa e melhoria da reflexão na pesquisa-ação. Interface (Botucatu), v. 20 (56), p. 65-76. DOI: http://dx.doi. org/10.1590/1807-57622015.0257

Marcolino, T. Q., Lourenço, G. F., Reali, A. M. M. R. (2017) “Isso eu levo para a vida": aprendizagem da prática profissional em uma Comunidade de Prática. Interface: Comun., Saúde, Educação (Botucatu), 21(61), p. 411-420. DOI: http://dx.doi.org/10.1590/180757622016.0099

Minayo, M. C. (2010) O desafio do conhecimento: pesquisa qualitativa em saúde. São Paulo: HUCITEC.

Mitchell, R., Unsworth, C. (2005) Clinical reasoning during community health home visits: expert and novice differences. Brit J Occup Therapy, 68(5), 215-23. DOI: http://dx.doi. org/10.1177/030802260506800505

Morato, G. G., Lussi, I. O. (2018) Contribuições da perspectiva de Reabilitação Psicossocial para a terapia ocupacional no campo da saúde mental. Braz J Occup Therapy, 26(4), 943-951. DOI: http:// dx.doi.org/10.4322/2526-8910.ctoARF1608

Morley, M. (2006) Moving from student to new practitioner: the transitional experience. Brit J Occup Therapy, 69(5), 231-33. DOI: http://dx.doi.org/10.1177/030802260606900506

Morley, M. (2007) Developing a preceptorship programme for newly qualified occupational therapists: action research. Brit J Occup Therapy, 70(8), 330-38. DOI: http://dx.doi. org/10.1177/03080226070700080

Morley, M., Rugg, S., Drew, J. (2007) Before preceptorship: new occupational therapists' expectations of practice and experience of supervision. Brit J Occup Therapy, 10(6), 243-53. DOI: http:// dx.doi.org/10.1177/030802260707000604

Nayar, S., Gray, M., Blijlevens, H. (2013) The competency of New Zealand new graduate occupational therapists: Perceived strengths and weaknesses. Austr Occup Ther Journal, 60 (3), 189-96. DOI: http://dx.doi.org/10.1111/1440-1630.12027

Ricci, T. E., Marques, I. P., Marcolino, T. Q. (2018) Occupational Therapy in mental health in Brazilian congresses: a scope review. Braz J Occup Therapy, 26 (4), 915-925. https://doi.org/10.4322/25268910.ctoAR1716

Rugg, S. (2003) Stressful expectations of junior occupational therapists. Brit J Ther and Rehabilitation, 10(1), 17-21. DOI: http://dx.doi. org/10.12968/bjtr.2003.10.1.13581

Scanlan, J. N., Still, M. (2013) Job satisfaction, burnout and turnover intention in occupational therapists working in mental health. Austr Occup Ther Journal, 60 (5), 310-318. DOI: http://dx.doi. org/10.1111/1440-1630.12067

Shafaroodi, N., Kamali, M., Parvizy, S., Hassani Mehraban, A., O’Toole, G. (2014) Factors affecting clinical reasoning of occupational therapists: a qualitative study. Med Jour Isl Rep Iran, 28(8), 1-10.
Schell, B. A. B., Schell, J. W. (2018) Clinical and Professional Reasoning in Occupational Therapy. Philadelphia: Wolters Klumer.

Schön, D. (2000) Educando o profissional reflexivo. Porto Alegre: Artmed. Spalding, N. (2000) The skill acquisition of two newly qualified occupational therapists. Brit J Occup Therapy, 63(8), 389-95. DOI: http://dx.doi.org/10.1177/030802260006300806

Toal-Sullivan, D. (2006) New graduates' experiences of learning to practice occupational therapy. BritJ Occup Therapy, 69(11), 513-24. DOI: http://dx.doi.org/10.1177/030802260606901105

Toledo, R. F., Giatti, L. L., Jacobi, P. R. (2014). A pesquisa-ação em estudos interdisciplinares: análise de critérios que só a prática pode revelar. Interface: Comunic., Saude, Educação, 18(51), 633-646. DOI: http://dx.doi.org/10.1590/1807-57622014.0026

Tryssenaar, J., Perkins, J. (2001) From Student to Therapist: Exploring the first year of practice. Am J Occup Therapy, 55 (1),19-27. DOI: http://dx.doi.org/10.5014/ajot.55.1.19

Unsworth, C., Baker, A. (2016) A systematic review of professional reasoning literature in occupational therapy. Brit J Occup Therapy, 79(1), 5-16. DOI: http://dx.doi.org/10.1177/0308022615599994 Wenger, E. (1998) Communities of practice learning, meaning and identity. Cambridge: Cambridge University Press. 
